\title{
Ensuring sustainable development of education of future maritime transport professionals by means of network interaction
}

\author{
Olena Dyagileva ${ }^{1}$, Nataliia Goridko ${ }^{2}$, Halyna Popova ${ }^{3}$, Serhii Voloshynov $^{3}$, and Alona Yurzhenko $^{4, *}$ \\ ${ }^{1}$ Kherson State Maritime Academy, Innovation Technologies and Technical Means of Navigation Department, Kherson, 73000, Ukraine \\ ${ }^{2}$ National Transport University, Department of Foreign Languages, Kyiv, 01010, Ukraine \\ ${ }^{3}$ Kherson State Maritime Academy, Innovation Technologies and Technical Means of Navigation Department, Kherson, 73000, Ukraine \\ ${ }^{4}$ Kherson State Maritime Academy, International Affairs Department, Kherson, 73000, Ukraine
}

\begin{abstract}
The article describes the concept of sustainable development, which is one of the modern trends of scientific research in the 21 st century. The analysis of scientific researches has been carried out in the context of the mentioned problem of sustainable development, the tendencies of development of the network interaction theory as factor of sustainable development of maritime education have been transformed into pedagogical practice of maritime higher educational establishments. The main objective of the article is to express the idea that the rapid development of information is the main impetus for the transformation of education, updating its content and forms, methods and technologies, improving the efficiency and accessibility of quality education. The process of network interaction on the example of creating an e-course for foreign students is substantiated. There was considered the possibility of modernizing the training of maritime professionals using modern information technologies (distance technologies, augmented reality and VR). The prospect of network interaction ideas has been proved, which is confirmed by the effectiveness of the introduction of the Moodle e-course for international entrants. It is shown that the students participate in network interaction, create the frame for successful adaptation of international students in Ukraine.
\end{abstract}

\section{Introduction}

The twenty-first century has opened risks exacerbation of civilization's unsustainable development, increasing obstacles to disturbance of biosphere equilibrium. According to the UN news, in the first twenty years of the new century 6,457 natural disasters have occurred in the world, affecting more than a third of the world's population [1].

In the era of globalization, there is a significant reorientation of the values of world civilization. The phenomenon of the explosion of digital technologies is resulting in the rapid development of ICT technologies and a diminished focus on the humanitarian, cultural component of human life. This leads to a violation of equilibrium in society. And scientists point to the emergence of a new stage of civilization development ecological-information civilization [2].

The concept of sustainable development is one of the modern trends of scientific research in the twenty-first century. But due to the lack of a common understanding of the "sustainable development" concept, the unified definition has not yet been created.

In 1987, the UN Commission on Environment and Development identified in the report "Our Common Future" the key idea of sustainable development as a development that meets the needs of the modern generation without sacrificing the ability of future generations to meet their personal needs. The International Maritime Organization (IMO) also reiterated this initiative, emphasizing that adopting this concept can help to increase awareness of the need for sustainable maritime development and to coordinate maritime policy worldwide [3].

Sustainable development is perceived by the international community as a benchmark and a goal of sustainable development for empowerment in addressing environmental and human factors.

The component of sustainable development is network interaction. Maritime education doesn't have any research in this field. Network cooperation is an effective method that allows future maritime specialists to adequately and timely respond to changes that take place, including: globalization and expansion of the international space of industrial enterprises; the need for quick adaptation to constantly changing environment; increased competition at various levels; development of information technology and knowledge economy.

The objective of the article is to show and analyze the practical implementation of network interaction to ensure sustainable development of education of future maritime transport professionals. This will help to

* Corresponding author: helen18@online.ua 
encourage changes in knowledge, skills, values and attitudes of students and entrants of a maritime higher educational establishment.

\section{Key results of research}

\subsection{Sustainable development concept in scientific discourse}

Philosophers give the following definitions of sustainable development: the creative evolution of a system, under which no transformations within the system, no external factors can bring it out of the state of dynamic equilibrium [4]; a form of hope for another "technological breakthrough" that will help to harmonize relations between the man and nature, as well as the transition to the noospheric type of human and nature existence [5]; the term "sustainable development" can be considered identical to the term "co-evolution of the man and the biosphere", which originates in the writings of $\mathrm{V}$. Vernadsky and K. Tsiolkovsky and places emphasis on the environment [4].

Turning to philosophical interpretations allows us to synthesize a new definition of "sustainable development" based on the modern concept of world civilization development. Society is on the verge of the fifth industrial evolution, when the convergence of the man and technology will lead to the emergence of new scientific and ideological approaches with the prospect of development in the third millennium. Development is always about growth, so it is imperative to determine whether such growth is conducive to building a sustainable future in the information society. Formation of a new stage of civilization development must take into account all new forms of transformation of society: global, regional, ecological-informational and informational-virtual as components of noospherogenesis.

It is the approach that will have a synthesizing positive role in creating a common theory of sustainable development [6, 7]. At the UNESCO World Education Conference in Aichi-Nagoya (November 2014), a declaration was adopted calling for urgent action to strengthen education for sustainable development and to expand its reach. As a result, in 2015, world leaders at the UN Headquarters proclaimed 17 Sustainable Development Goals, with 4 goals: ensuring inclusive and equitable quality education and promoting lifelong learning opportunities for all.

Scientists create a model of sustainable development at the conceptual-theoretical level, and the next stage is that education itself will shape the sphere of people's consciousness. So, as A. D. Ursul, sustainable development education is not only a prerequisite for achieving sustainable development, but also a priority for it [8].

And future education of sustainable development will have a system-leading character, fulfilling the function of training a person for leading actions in the conditions of global anthropoecological crisis and leaving it on the way to transition to sustainable development. Under the concept of advancing we will understand the process of evolution and advancement for the better.

Modern researchers place intellectual, spiritual and rational-information factors and resources, which have no restrictions unlike material and natural, and are the key to the survival and further development of civilization.

According to scientists, informatization and virtualization of human activity remove virtually all restrictions, all constants and behaviors that accompanied man on the path of civilization, resulting in the loss of landmarks [9]. And education itself can be the engine of change for the formation and greening of consciousness, awareness and international cooperation for the orientation of content and forms of education to our common sustainable future.

The rapid development of information is a major impetus for the transformation of education, updating its content and forms, methods and technologies, improving the efficiency and accessibility of quality education. The transition to the information model of society makes it necessary to become a type of education that expands its scope in the world of educational space, blurs the boundaries and changes the usual norms. At the same time, information flows and actions on a planetary scale can become risk factors and lead to catastrophe. Modern society recognizes that information is the most important strategic resource that is limitless, and the use of information, on the contrary, leads to an increase in the volume of these resources.

But there is a contradiction when society is already immersed in the information age and the consciousness of the majority remains in the time of the industrial era. "Humanity has come to the threshold beyond which new morality, new knowledge, a new mentality, and a new system of values are needed". Authors of [10] forms a clear "environmental imperative": "What was permissible in the past is already unacceptable today".

Therefore, it is imperative to develop such a system of education, where the information culture will foster the development of information awareness, which will make it possible to build a proper cybersecurity system, both state and personal. In the problem of formation of human responsibility for life on the planet, the central issue is the qualitative characteristics of man, which shape the integrity of the outlook of the individual, the development of independent, critical thinking.

It is determining the need to create a new quality of education that will construct new pedagogical tools capable of providing a civilizational transformation, building a world of sustainable development, as the basis of a new outlook and sustainable way of life.

According to the UNECE's Strategy for Education of Sustainable Development, the most important thing is to create competences for self-education and selfidentification, work as a team, learn to live together, and learn to change ourselves and the environment. All these competences cannot be formed without advanced systemic thinking that defines the unity of consideration in any activity of the economic, social and environmental component, past, present and future, personal and global, morality and law ones. 
Characteristic features of the noospheric-information (leading) model of education are determined by: globalization, continuity, personal orientation, increasing the diversity of educational standards and specialties, the use of distance education, networking [11].

The IMO supports global standards for sustainable development (safety and environmental protection) which are important for sea and river transport. The IMO has developed its own standards, which are based on economic, social and environmental sustainability, where shipping safety is a top priority.

At a symposium on World Maritime Day, September 26, 2013, the Secretary General of the International Maritime Organization, Koji Sekimizu, noted that since the global economy cannot exist without shipping, shipping will play a central role if the world wants to achieve sustainable development. At the global maritime trade market, shipping is one of the main links in multidimensional transport processes in the structure of the sea and river transport industry.

The emphasis in the maritime industry is the idea that the future depends on competent maritime professionals, and the establishment and research centers on maritime education should play an important role in this. They have the potential to introduce new innovative and digital teaching methods.

The Report about Maritime Sustainability highlights that education and training in developing countries are critical to a sustainable shipping system [12].

D. Krause, S. Diop, B. Brown and D. Troost say that sustainable maritime development depends on knowledge of the marine environment and access to it through training [13]. They conclude that maritime training and education is not just one of the aspects of sustainable maritime development, but also a tool to accelerate the proliferation of the paradigm in the marine industry.

\subsection{Sustainable development of networking cooperation}

The spheres of social activity of the information society are education, scientific and technological sphere, mass communications, information service and maintenance of various networks of information devices [3].

The issues of educational informatization are covered in the scientific works of A. V. Spivakovsky, S. O. Semerikov, V. V. Osadchyi, K. P. Osadcha, A. M. Striuk, Y. O. Modlo, M. S. Lvov, V. N. Kukharenko.

V. V. Osadchy and V. S. Kruglyk highlight the following global trends in the development of information technology in education: understanding ICT competences as a means of gaining all other competences for life-long learning; ensuring equal access to computer equipment and information on the Internet to all sections of the population; focusing on the free access of each member of society to the Internet information resources and the participation of everyone in the information society; creating the information society that respects human dignity, freedom and human rights; use of information and communication technologies for the benefit of people; development of distance or virtual type of training; introduction of a system for assessing the state of informatization of an educational institution; introduction of a global cybersecurity culture; implementation through ICTcontinuous and adult education, professional retraining, lifelong learning.

This leads to the modernization of the training of maritime professionals using modern information technologies, among which distance technologies, augmented/virtual reality technologies stand out.

For students in the information society era, Internet space is an important medium of communication. The online environment performs important functions in the process of youth socialization - informative, regulatory, educational, cognitive, socially-communicative ones; creates an opportunity to find appropriate reference groups and meet the need for self-fulfillment of young people [14].

Networking, as a methodological principle, is the basis of a new form of education - the networking, which is legalized in Article 9, paragraph 5 of the Law of Ukraine "On Education", which states that the networking form of education is a way of organizing education of the educational recipients of education, thanks to which the acquisition of the educational program takes place with the participation of different educational entities that interact on a contractual basis $[15,16]$.

The use of distance learning technologies (e-learning, m-learning) covers not only specific specialties or educational programs, but is an important strategic tool for the development and positioning of higher education institutions, enhances the innovative potential of the whole organization, and as a consequence increases the competitiveness of its graduates. The prevailing era of Web 2.0, an era of interactive web resources and communities that allows the user to become actively involved in the processes of their dissemination, discussion and development, as well as the creation of individual learning and social spaces, controlled even from a mobile phone, cannot leave the teaching system unchanged in a static web-based academy that only reads them from your computer and doesn't allow communication or interaction.

The implementation of distance learning technologies should include: communication and exchange of information at a distance; taking into account individual cognitive abilities of students (personalization); interactivity; mobility and virtual collaboration. All this can be realized in the process of professional training of the cadets of the Maritime Academy through the use of electronic and mobile training, virtual and augmented reality technologies on simulators. That is why today the direction of distance (electronic) education development is needed.

The scientists who studied innovative technologies in the training of future maritime professionals are following: I. Popovych, O. Blynova, M. Aleksieieva, P. Nosov, N. Zavatska, O. Smyrnova [14], A. Yurzhenko, H. Popova [17], V. Chernyavsky, 
O. Volska, N. Panchenko, A. Vasiljevs, T. Bezverhnuik, S. Voloshynov [18].

The development of computer networking technologies is becoming one of the foundations for the distance learning, e-learning and mobile learning, which are effectively used for various forms of learning, including blended learning.

According to the modern level of development of distance learning technologies, there are creation and use of software complexes and e-learning tools of different orientation, including learning management systems (LMS), which integrate tools for administration, communication, assessment of knowledge, development and support of distance learning courses [19].

Therefore, a flexible education system is essential, enabling students to acquire knowledge where and when it is convenient for them; and it is necessary for the student to learn independently to work with information, acquire educational and subsequently professional competence [20,21].

Nowadays the competency-based approach is the methodological basis of distance learning [22, 23]. It allows each student to: actively engage in the process of mastering new subject content; learn operational and technical means of performing activities; create their own learning trajectory; independently plan and control the rhythm of training; independently plan and control the level of competence formation.

\subsection{Organization of networking cooperation at Kherson State Maritime Academy}

The ultimate goal of Kherson State Maritime Academy (KSMA) cadets' training is not the acquisition of knowledge, skills and competences, but the level of their competences achievement, i.e. the ability to use their knowledge, skills and abilities in a particular situation, and in maritime education even in emergency situations $[24,25]$.

KSMA took out a charter for training foreign nationals in basic accredited fields (specialties) of the maritime industry on June 30, 2010.

International students from Azerbaijan, Armenia, Bangladesh, Belarus, Ghana, Guinea, Georgia, Kazakhstan, Egypt, Cameroon, Cyprus, Ivory Coast, Lebanon, Libya, Moldova, Nigeria, Pakistan, Portugal, Russia, Tunisia, Turkmenistan, Turkey study at KSMA. As of December 1, 2019, 120 foreign nationals are studying at KSMA, 78 of them are full-time and 39 are part-time students; 8 English language classes are formed; 3 students are at the preparatory department.

Successful adaptation of international students to study in Ukraine is possible in case of creation of a comfortable infrastructure for life for them, rapid adaptation to local traditions.

For this purpose, a questionnaire of international students studying at KSMA was conducted.

Questionnaires consisting of 23 questions were used for the study, concerning the characteristics of students' adaptation to learning, their attitude to the values of a healthy lifestyle, forms of leisure activities and more
(Fig. 1).

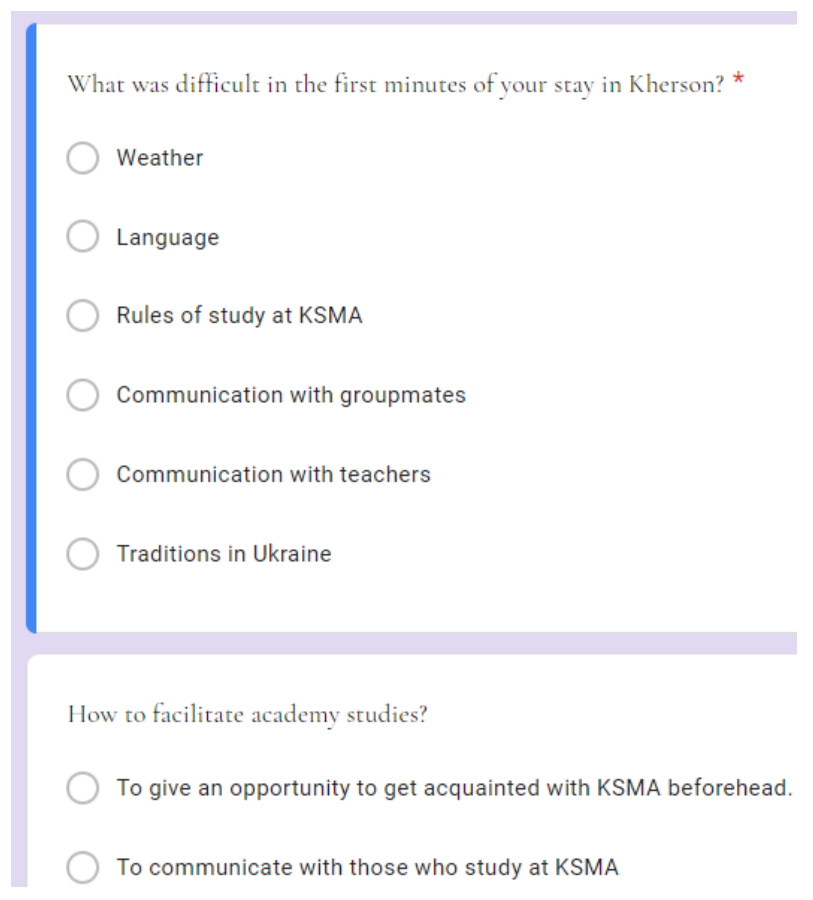

Fig. 1. Part of the questionnaire for foreign entrants.

The survey was conducted among 110 international students aged 17 to 22 years, studying at various courses and faculties of the Academy. It is of interest to study the issue of leisure and employment. The questionnaire raised the difficulty they encountered in Ukraine. They were ignorant of the Ukrainian language (16.8\%), climate $(24.4 \%)$, but there were also those who had no difficulties $(20.2 \%)$. In order to support future entrants and to accelerate the adaptation of international students to the educational environment of the academy and living conditions in Ukraine, a course on the Moodle platform was created.

The main goal of the course is to pre-study English and to find out more about Ukraine, Kherson and Ukrainian traditions. The beginning of it consists of words of welcome, KSMA logo, main competences to achieve by the end of the course, news, information about author and teacher, online chat, questionnaire, check your competency questions, forum and different questionnaires (Fig. 2).

The course consists of the following topics to study:

- 1st Module: Unit 00 Personal data; Unit 01 People and places in Ukraine; Unit 02 Kherson;

- 2nd Module: Unit 03 Free time; Unit 04 Place to live; Unit 05 Holidays; Unit 06 Shops;

- 3rd Module: Unit 07 Family and Friends;

- 4th Module: Unit 08 Experience; Unit 10 Travel;

- 5th Module: Unit 11 Food.

To study separate topics of the course, gamified activities were created by a teacher (e.g. topic "Ukraine" in Fig. 3).

The gamified activities were created with the help of learningapps.org. The number of templates on this platform to create gamified activities is 24 . The example of a gamified activity to study how much of Ukraine 
foreign entrants know is shown in Fig. 4.

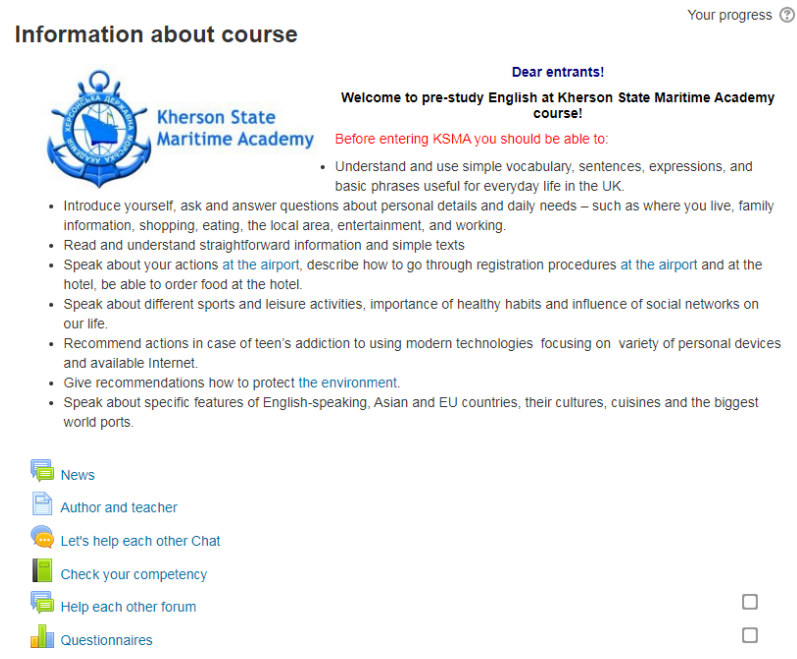

Fig. 2. The beginning of the e-course for foreign entrants in Moodle LMS of KSMA.

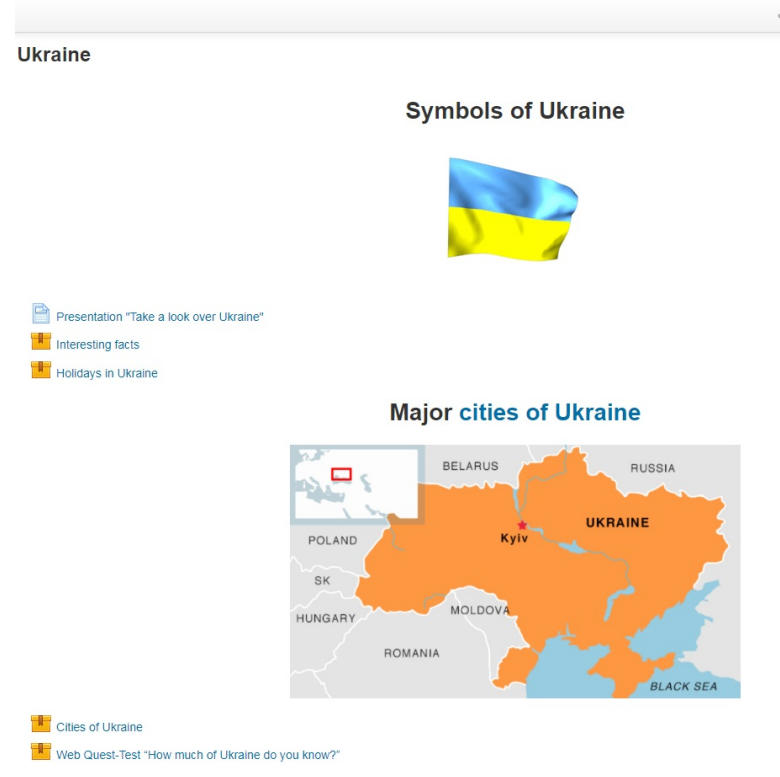

Fig. 3. Topic "Ukraine" in the Moodle e-course for foreign entrants.

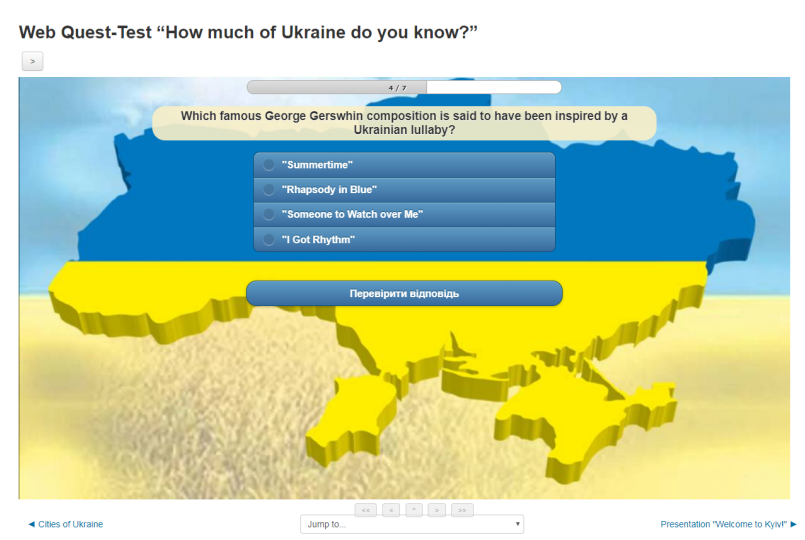

Fig. 4. Gamified activity "How much of Ukraine do you know?"

The course consisted also of forums to communicate with other students and cadets of KSMA. The forums allow encouraging discussion and improving communication, increase collaboration and provide better engagement. In forums of the e-course students can easily find assistance and support. The use of forums has many advantages (they improve communication, increase collaboration, and ensure better engagement).

One of the activities is video watching. During English classes at KSMA students of the second year made subtitles for various videos about Kherson and KSMA and with the help of teacher downloaded them to the course for foreign entrants. The task for entrants is to watch the videos and, using e-Glossary, to find the definitions of unknown words.

The example of the part of the e-course is shown in Fig. 5. This figure shows Unit 10 "Travel" of the $4^{\text {th }}$ Module. It includes the following:

- gamified activities on matching words with definitions;

- listening and writing the answers;

- matching pictures with their names;

- multiple choice;

- studying colorful presentation (Prezi website);

- watching videos about Kherson;

- writing unknown words into Glossary; doing a test (Stop and check).

\section{10 Travel}
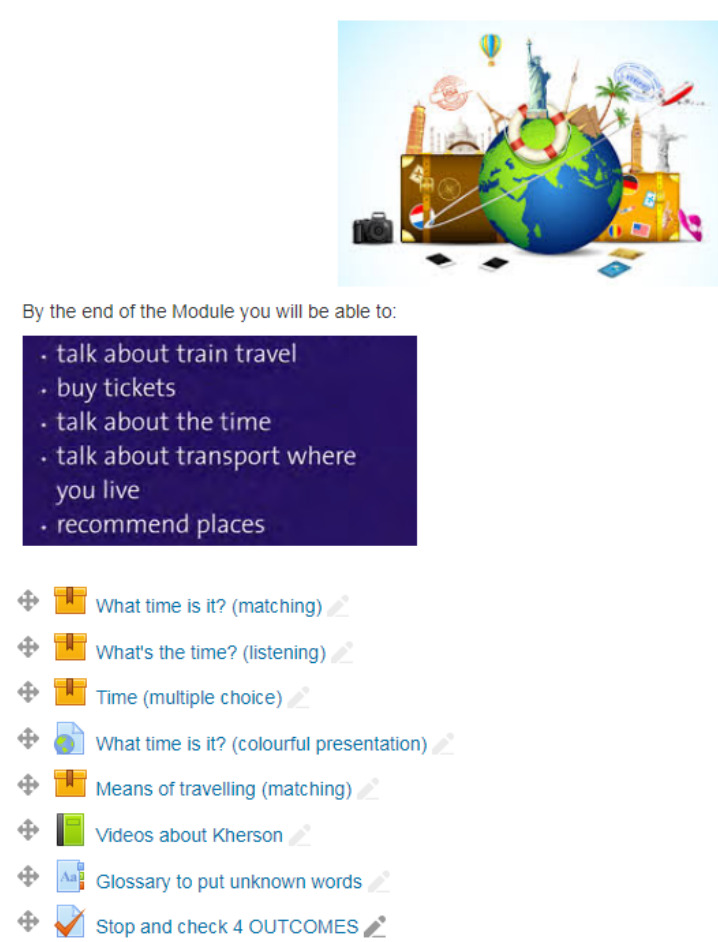

Fig. 5. Unit 10 Travel.

One of gamification elements is use of badges. It is realized with the help of Moodle LMS option - badges (symbolic rewards given to students for different achievements and displayed on a user's profile). Their main goal is to show the progress and motivate future students to succeed. The part of different badges is represented in Fig. 6. 


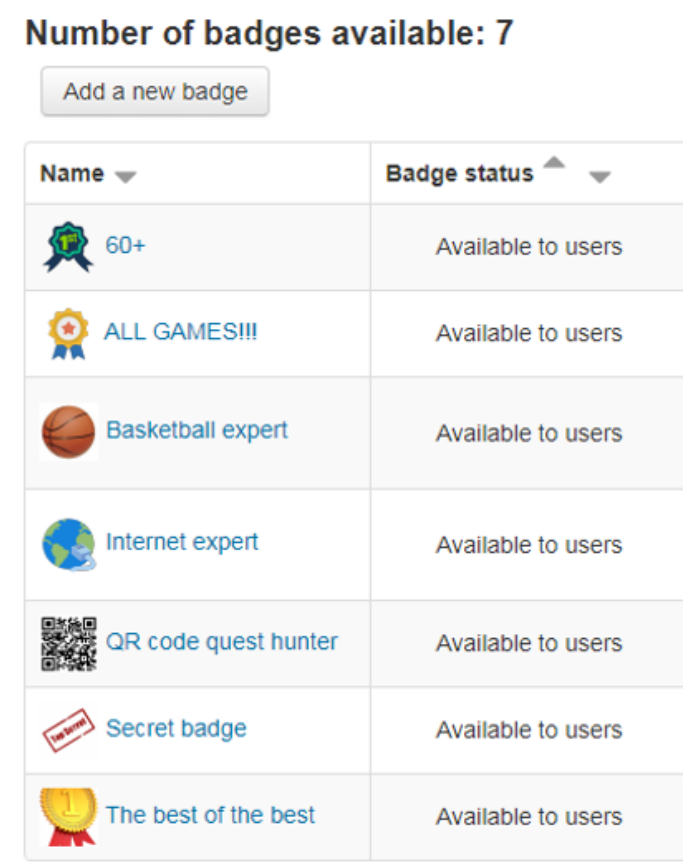

Fig. 6. Examples of badges given on the e-course for different achievements.

One of the advantages of using such a course use for foreign entrants is implementation of the principle of individual educational trajectory. The e-course is flexible in content creation and various assessment tools. Conduction of formative assessment allows teachers and tutors to identify the educational material that the cadet has not mastered. After testing, a new training program is formed from this material with the use of new training content, and so the training is organized until the results of the formative assessment are satisfactory.

Another advantage of the e-course is the opportunity to receive fast feedback, possibility of visual presentation of educational material and critical reflective learning and most importantly -motivation increase [26]. In this way Moodle LMS and the implementation of the idea of advanced professional education will not only significantly increase the possibility of a person's self-determination in the world of professional labour, but also help a person to adapt to the conditions of a dynamically changing maritime industry [27, 28]. And by increasing the general and professional literacy of future maritime transport specialists in constantly changing environment, it will contribute to the effective development of production and the economy as a whole.

\section{Conclusions}

Noospheric catastrophes require substantial analysis, and all the forces of the world community are aimed at combating them and their consequences.

The ways out of this situation, according to the concept of sustainable development, consist primarily of the technical and technological, information and computer modernization of the society's structure. Education is the key to sustainable development, because through education values, preferences, lifestyles are introduced that are necessary for the development of society. The basis for quality education today should be fundamental, cross-curricular, scientific and systematic, the formation of critical thinking, problematic learning, active participation of educationalists in the process of obtaining knowledge. And lifelong learning is an indicator of a person's effectively developed professional competence.

The education for sustainable development is now at the stage of forming meaningful educational conditions for the formation of such a generation. As the result of our study, the e-course in Moodle LMS for network interaction was created. This is the factor of sustainable development. Research in the field of sustainable development, as a rule, requires cooperation between scientists of different disciplines, between scientists and representatives of business and society, as well as cooperation between educational institutions and universities of different countries. Mutual learning based on real case studies requires an interdisciplinary approach to solve problems in an ever-changing world and to increase the level of network interaction and selforganization. Thus, one of the promising tools for improving the quality of education in the interests of a sustainable future is the development of effective tools and models of network interaction based on modern distance technologies. We see the prospects of further research we see in expanded cooperation and established networking with foreign institutions.

\section{References}

1. UN News, Natural disasters have claimed the lives of 600,000 people worldwide over the past 20 years (2016)

2. V. Pozhuyev, ZASEA Humanitarian Newsletter 51, 5 (2012)

3. World maritime day: a concept of a sustainable maritime transportation system (2013)

4. L. Mantatova, International Interdisciplinary Encyclopedic Dictionary (2003)

5. R. Chuchukalova, Sustainability Concentration Prehistory (2011)

6. O. Kuzinga, The Essence and Content of the Concept of Sustainable Development: from Theory to Practice: the Example of Sweden, Dissertation, 2009

7. V. Kuibar, "Ecological Information Society" as a Stage in the Development of Global Civilization (Ideological and Methodological Aspect), Dissertation, 2012

8. A. Ursul, Bulletin of Culture and Arts 3 (2017)

9. A. Ursul, A. Romanovich, Philosophical Studies 6 (2001)

10. V. Inozemtsev, Yu. Inozemtseva, The problem of information resources in the conditions of the formation of a noospheric ecological civilization. News MGTU “MAMI” 4, 18 (2013) 
11. E. Dzyatkovskaya, Education for Sustainable Development at School. Cultural Concepts. "Green Axioms." (Moscow, 2015)

12. P. Gaponyuk, Education and Science 7, (2001)

13. D. Krause, S. Diop, B. Brown, D. Troost, The Marine Environment and Sustainable Development: Law, Policy, and Science (1993)

14. V. Kruglyk, V. Osadchyi, Historical Approach to Modern Learning Environment. Integration of Education 23 (2019.

15. Y. Modlo, S. Semerikov, S. Bondarevskyi, S. Tolmachev, O. Markova, P. Nechypurenko, CEUR Workshop Proceedings 2547, 217-240 (2020)

16. Verkhovna Rada of Ukraine, Legislation of Ukraine (2017)

17. A. Yurzhenko, H. Popova, CEUR Workshop Proceedings (2019)

18. V. Cherniavskyi, S. Voloshynov, O. Volska, N. Panchenko, A. Vasiljevs, and T. Bezverhnuik, in ICTE in Transportation and Logistics, 1 st edn. (Springer International Publishing, 2019)

19. H. Zborovsky, E. Shuklina, Education as a resource of the information society. Sociological Studies 7 (2005)

20. N. Moiseev, Modern Anthropogenesis and Civilizational Faults. Ecological and Political Analysis (MNEPU, Moscow, 1995)

21. Y. Modlo, S. Semerikov, P. Nechypurenko, S. Bondarevskyi, O. Bondarevska, S. Tolmachev, CEUR Workshop Proceedings 2433, 413-428 (2019)

22. A. Spivakovsky, L. Petukhova, V. Kotkova, Y. Yurchuk, CEUR Workshop Proceedings 2393, 1011-1024 (2019)

23. O. Shalar, V. Huzar, Y. Strikalenko, S. Yuskiv, V. Homenko, A. Novokshanova, Psychopedagogical aspects of interaction between personality traits and physical qualities of the young gymnasts of the variety and circus studio. Journal of Physical Education and Sport 19 (2019)

24. A. Striuk, M. Rassovytska, S. Shokaliuk, CEUR Workshop Proceedings 2104 (2018)

25. M. Sherman, Y. Samchynska, The information and reference system on rare and endangered species of animals as a computer tool for the formation of future ecologists digital competency. Information Technologies and Learning Tools 72 (2019)

26. A. Golovan, I. Gritsuk, V. Popeliuk, O. Sherstyuk, I. Honcharuk, R. Symonenko, V. Saravas, M. Volodarets, M. Ahieiev, D. Pohorletskyi, I. Khudiakov, Features of mathematical modeling in the problems of determining the power of a turbocharged engine according to the characteristics of the turbocharge. SAE International Journal of Engines (2020)
27. L. Tovazhnyanskij, V. Kravets, V. Kukharenko, Information space of Ukraine for lifelong learning, Control Systems and Machines 3-4 (2002)

28. O. Kolgatin, L. Kolgatina, N. Ponomareva, E. Shmeltser, Systematicity of students' independent work in cloud learning environment. CEUR Workshop Proceedings 2433, 184-196 (2019) 